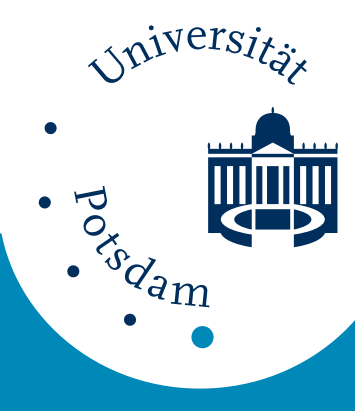

Universität Potsdam

O. Albrecht, W. Cumming, W. Kreuder, A. Laschewsky, H. Ringsdorf

\title{
Monolayers of rod-shaped and disc-shaped liquid crystalline compounds at the air-water interface
}

first published in:

Colloid \& Polymer Science. - 264 (1986), 8, pp. 659-667

ISSN (print) 0303-402X

ISSN (online) 1435-1536

DOI 10.1007/BF01469526

Postprint published at the Institutional Repository of the Potsdam University:

In: Postprints der Universität Potsdam :

Mathematisch-Naturwissenschaftliche Reihe ; 79

http://opus.kobv.de/ubp/volltexte/2008/1712/

http://nbn-resolving.de/urn:nbn:de:kobv:517-opus-17124

Postprints der Universität Potsdam

Mathematisch-Naturwissenschaftliche Reihe ; 79

ISSN 1866-8372 


\title{
Monolayers of rod-shaped and disc-shaped liquid crystalline compounds at the air-water interface
}

\author{
O. Albrecht ${ }^{1}$ ), W. Cumming ${ }^{2}$, W. Kreuder ${ }^{1}$ ), A. Laschewsky ${ }^{1}$ ) and H. Ringsdorf ${ }^{1}$ ) \\ 1) Institut für Organische Chemie, Universität Mainz, F.R.G., and \\ $\left.{ }^{2}\right)$ Polaroid Corp., Cambridge, Mass, U.S.A.
}

\begin{abstract}
Calamitic (rod-shaped) and discotic (disc-shaped) thermotropic liquid crystalline (LC) compounds were spread at the air-water interface, and their ability to form monolayers was studied. The calamitic LCs investigated were found to form monolayers which behave analogously to conventional amphiphiles such as fatty acids. The spreading of the discotic LCs produced monolayers as well, but with a behaviour different from classical amphiphiles. The areas occupied per molecule are too small to allow the contact of all hydrophilic groups with the water surface and the packing of all hydrophobic chains. Various molecular arrangements of the discotics at the water surface to fit the spreading data are discussed.
\end{abstract}

Key words: Monolayers, liquid crystals, discotics.

\section{Self-organisation of amphiphiles and mesogens}

The self-organization of amphiphiles in aqueous media [1], and the self-organization of mesogenic compounds in liquid crystalline (LC) phases [2] has been investigated intensely in the past. Recently, the combination of amphiphilic and mesogenic properties of thermotropic LCs has been realized, and spreading experiments at the air-water interface were performed [3-7]. In addition, the functionalization of amphiphilic compounds led to the incorporation of rod-shaped mesogenic units in amphiphiles, such as biphenyl $[6,8]$, stilbene $[9,10]$, azobenzene [11-14], benzylidenaniline [15] or bipyridine [16,17]. In these compounds the rod-shaped units function as chromophores, fluorescence markers or highly polarizable units. However, the mesogenic character of these functional units was rarely considered.

A different type of liquid crystalline amphiphiles derives from substituted benzoic or cinnamic acids such as 4-octadecyloxy-cinnamic acid [18-21]. But, their thermotropic LC properties are based on the formation of rod-shaped mesogenic units by dimerization of the carboxylic acid groups, a highly improbable interaction in aqueous systems.

\section{Rod-shaped and disc-shaped amphiphiles at the air-water interface}

To study the influence of the form-anisotropic units in amphiphiles on the monolayer [22] self-assembly, different thermotropic LCs were investigated. Rodshaped mesogens, which form calamitic mesophases, as well as disc-shaped mesogens, which form discotic mesophases, were spread. It has to be kept in mind that thermotropic LC behaviour is normally described in bulk. This phase behaviour cannot be related directly to the aggregation at the air-water interface. Thus, spreading does not necessarily result in 'monomolecular' LC phases with a structure analogous to freely suspended LC films [23]. For instance, the compounds investigated are studies in monolayers well below the transition temperature from bulk crystalline to bulk liquid crystalline phases.

Tables 1 and 2 list the compounds investigated, their structures and their thermotropic LC characteristics. The compounds 1-6 have rod-shaped mesogenic units. 1-4 consist of a hydrocarbon chain attached to a mesogen, carrying polar substituents such as cyano or nitro groups. The polar groups can be considered as hydrophilic heads. Hence, these LCs resemble the classical 
Table 1 a

CALAMITIC LIQUID CRYSTALS

1

$\mathrm{C}_{17} \mathrm{H}_{35}-\mathrm{COO}-\mathrm{N}=\mathrm{N}-\mathrm{COOH}$

$2 \quad \mathrm{C}_{18} \mathrm{H}_{37}-\mathrm{O}-\mathrm{N}=\mathrm{N}-\square-\mathrm{NO}_{2}$

$3 \quad \mathrm{C}_{18} \mathrm{H}_{37}-\mathrm{O}-\mathrm{O}=\mathrm{N}-\mathrm{CN}$

$4 \mathrm{C}_{7} \mathrm{H}_{15}-\mathrm{O}$

MONOMERS OF CALAMITIC POLYMERIC LIQUID CRYSTALS

5

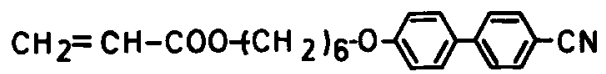

$\underline{6}$

$\left.\mathrm{CH}_{2}=\mathrm{CH}-\mathrm{COO}+\mathrm{CH}_{2}\right)_{6}-0-\mathrm{COO}-\mathrm{CN}$

amphiphilic structure of fatty acids. But, according to their unusually long hydrocarbon tails, $1-3$ show thermotropic LC behaviour in a narrow temperature range only. The polymerizable mesogenic compounds 5 and 6 are precursors of polymeric LCs $[27,28]$. As the additional acrylate group at the end of the hydrophobic tail is sufficiently hydrophilic to act as a head group [49], 5 and 6 are amphiphiles with two polar heads.

The compounds 7-11 are typical discotic LCs [24, 25 ], with hydrocarbon chains attached to the discoid aromatic cores by ester or ether linkages. Although they do not resemble the classical amphiphilic structure of lipoids, 7-11 can be considered as amphiphiles because they combine both hydrophilic and hydrophobic elements [44].

The amphiphilic character of 1-11, and their insolubility in water do not necessarily imply the ability to form monomolecular layers. Instead, microcrystallites
Table $1 \mathrm{~b}$

\section{DISCOTIC LIQUID CRYSTALS}

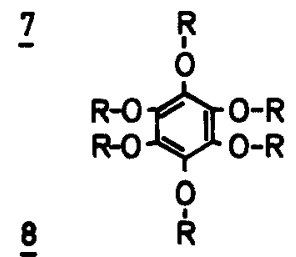

$$
\begin{aligned}
& R=-C O-C_{7} H_{15} \\
& R=-C O-C_{9} H_{19}
\end{aligned}
$$

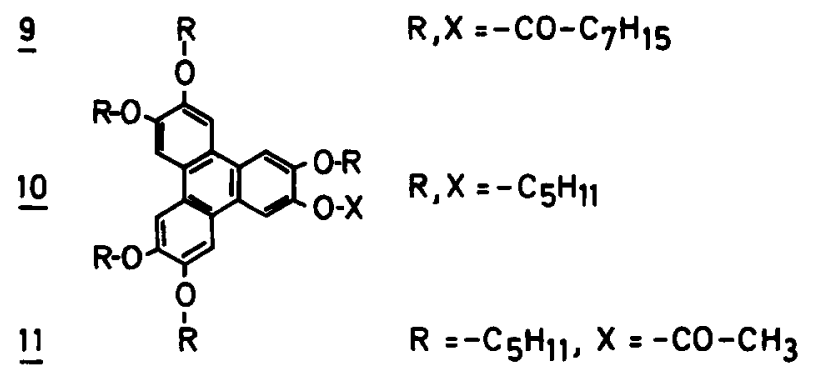

or oily phases could be formed at the air-water interface, phenomena often observed. Such aggregates apparently compete with monolayer formation. Their spreading mimics monolayer assembling, showing a dependence of tine surface pressure on the surface concentration. But, a defined collapse point is missing, and high surface pressures are found only for very high sur-

\begin{tabular}{|c|c|c|c|c|}
\hline Compound & \multicolumn{2}{|c|}{ Phase transitions } & Reference & Comment \\
\hline 1 & $k 178$ s $221 n$ & $237 d$ & & \\
\hline 2 & $k 92 s$ & $94 i$ & & \\
\hline 3 & $k 111(s$ 105) & $i$ & & Monotropic LC \\
\hline 4 & $53 n$ & $75 i$ & 42 & \\
\hline 5 & $k$ & $70 i$ & 27 & Polymers are LC \\
\hline 6 & $k$ & $72 i$ & 28 & Polymers are LC \\
\hline 7 & $\begin{array}{lll}k & 81 & D_{r d}\end{array}$ & $87 i$ & 24 & \\
\hline 8 & $k 80\left(D_{r d} 77\right)$ & $i$ & 24 & Monotropic LC \\
\hline 9 & $\begin{array}{lll}k & 62 & D_{r d}\end{array}$ & $125 i$ & 43 & \\
\hline 10 & $k 68 \quad D_{b o}$ & $123 i$ & 29 & \\
\hline 11 & $k 54 \quad D_{b o}$ & $161 i$ & 29 & \\
\hline
\end{tabular}

Table 2. Phase behaviour of compounds 1 to 11

$k=$ crystalline, $s=$ smectic,$n=$ nematic, $d=$ decomposition, $i=$ isotropic, $D_{r d}=$ columnar rectangular disordered, $D_{b o}=$ columnar hexagonal ordered 
face concentrations, i. e. at apparent areas per molecule occupied which are too small for even the most dense packing of the molecules in a monolayer. This behaviour of spread amphiphiles is often misinterpreted, and a defined monomolecular structure is assumed by mistake, giving rise to much confusion in the literature [36].

\section{Materials and methods}

\section{Materials}

The 4-(4-octadecanoyloxyphenylazo)benzoicacid 1 was synthesized by reaction of octadecanoylchloride with 4-(4-hydroxyphenylazo)benzoic acid in the presence of triethylamine. 4-octadecyloxy-4-nitroazobenzene 2and 4-(4-octadecyloxyphenylazo)benzonitrile 3 were prepared from octadecylbromide and the corresponding 4-(4-hydroxyphenylazo)benzene derivatives by the method of Claisen [26]. 4-(4-heptyloxyphenyl)benzonitrile 4 was purchased from HoffmannLa Roche. The synthesis of 6-(4-cyano-4-biphenylyloxy)hexyl acrylate 5, 6-(4-(4-cyanophenyloxycarbonyl)phenyloxy)hexyl acrylate 6, 2,3,6,7,10,11-hexakis(pentyloxy)triphenylene 10 and 3,6,7,10,11-pentakis(pentyloxy)-2-triphenylenyl acetate 11 have been described previously [27-29]. The benzenehexayl hexakis(octanoate) 7 and the benzenehexayl hexakis(decanoate) 8 were prepared by esterification of hexahydroxybenzene [48] with octanoyl chloride and decanoylchloride respectively [47]. 2,3,6,7,10,11-triphenylenehexayl hexakis(octanoate) 9 was prepared by the esterification of hexahydroxytriphenylene [46] with octanoylchloride in the presence of pyridine.

\section{Metbods}

Spreading experiments of 1 to 11 were performed on a computer controlled film balance [30]. In case of 2 and 3 , the Wilhelmi pressure pick up system was exchanged by a Langmuir pressure pick up system. All films were spread on pure water subphase. The water was distilled and purified by a Milli $Q$ water purification system (Millipore Corp.). 1 and 2 were spread from chloroform solutions, 3 from dichloromethane solutions, 4 to 6 from hexane-ethanol mixtures $(9 \mathrm{v} /$ $1 \mathrm{v}), 7$ to 11 from hexane solutions. The concentrations of the spreading solutions were about $0.2 \mathrm{mg} / \mathrm{ml}$. In case of 2, the concentration of the spreading solution was kept at $0.05 \mathrm{mg} / \mathrm{ml}$ to avoid crystallisation on spreading. The compression rates were about 0.05 $\mathrm{nm}^{2} /$ molecule min for the calamitic LCs 1 to 6 , and

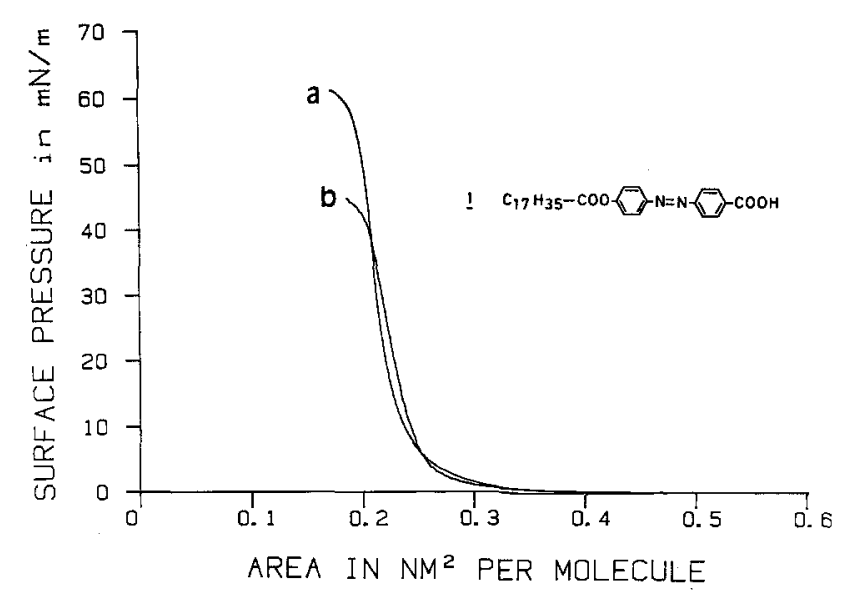

Fig. 1. Surface pressure-area diagrams of $1: a=$ at $20^{\circ} \mathrm{C} ; b=a t 40^{\circ} \mathrm{C}$

about $0.2 \mathrm{~nm}^{2} /$ molecule min for the discotic LCs 7 to 11.

\section{Spreading behaviour of the calamitic liquid crystals 1-6}

Figures 1-6 present the surface pressure $(\pi)-$ area (A) diagrams of the calamitic LCs 1-6. The LCs 1-3 with long hydrocarbon tails form monolayers in the condensed phase at room temperature. The collapse area is about $0.2 \mathrm{~nm}^{2} /$ molecule, the collaps pressures are above $40 \mathrm{mN} / \mathrm{m}$ (Figs. 1 - 3). This corresponds to a tight packing of the hydrocarbon chains as found for fatty acids and alcohols [22]. Compared to the cyanoazobenzene 3 [13], the nitrile 4 is characterized by a short aliphatic chain. 4 shows the formation of an expanded phase at room temperature: The reduction of the length of the hydrophobic chain causes the

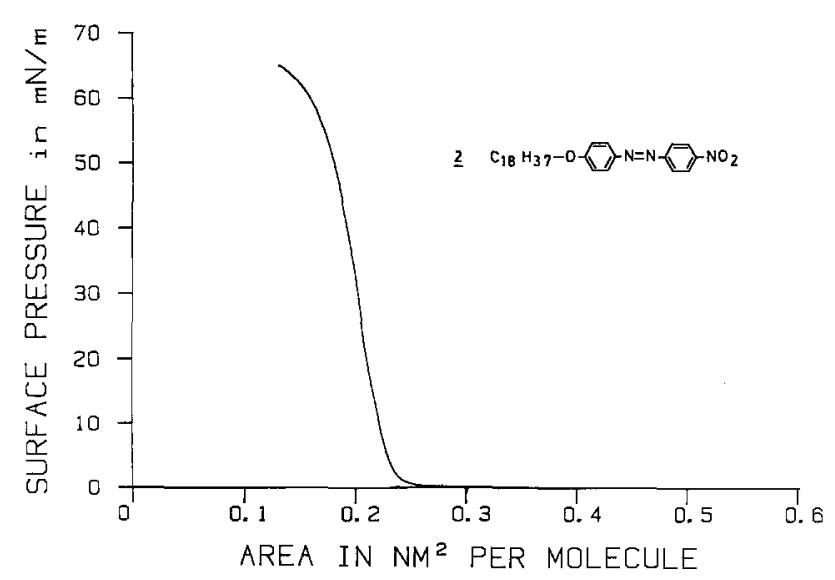

Fig. 2. Surface pressure-area diagram of 2 at $20^{\circ} \mathrm{C}$ 


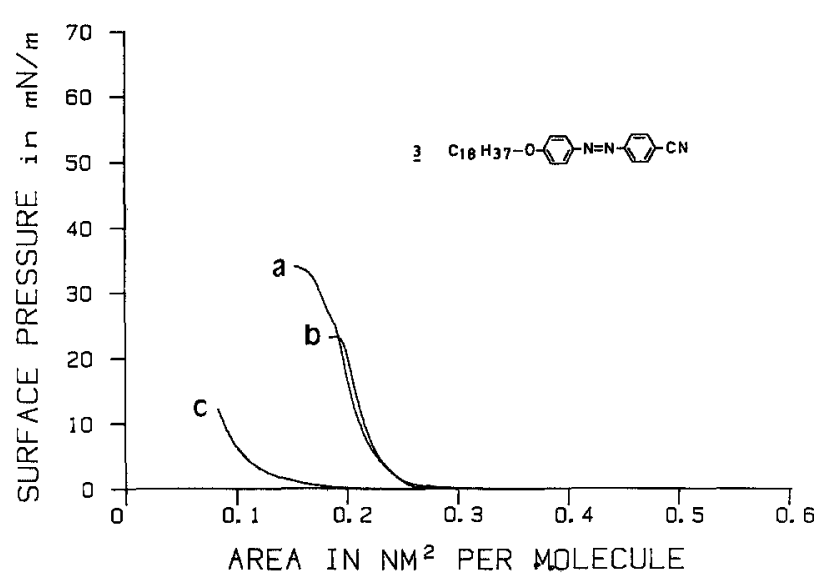

Fig. 3. Surface pressure-area diagrams of $3: a=a t 20^{\circ} \mathrm{C} ; b=a t$ $30^{\circ} \mathrm{C} ; \mathrm{c}=$ at $40^{\circ} \mathrm{C}$

decrease of the phase transition temperature [22], in agreement with the spreading behaviour of classical amphiphiles. Thus, the classical amphiphilic structure of the LCs 1-4 results in classical monolayer behaviour.

An unususal feature of 1-3 is the extreme rigidity of their condensed monolayers. Possibly, the rigidity is due to interactions of the aromatic units. Whereas the LCs 1 and 2 show stable, condensed monolayers up to $45^{\circ} \mathrm{C}$, the nitrile 3 does not form a monolayer above $35^{\circ} \mathrm{C}$ at all. The melting of the chains leads to an oily phase without collapse point (Fig. 3).

The $\pi$-A diagrams of $1-3$ (Figs. 1-3) show a tight packing of the hydrocarbon chains at the collaps point. One is thus tempted to relate the collaps area per molecule of $0.2 \mathrm{~nm}^{2}$ to a vertical orientation of the aromatic chromophores at the water surface. However, in con-

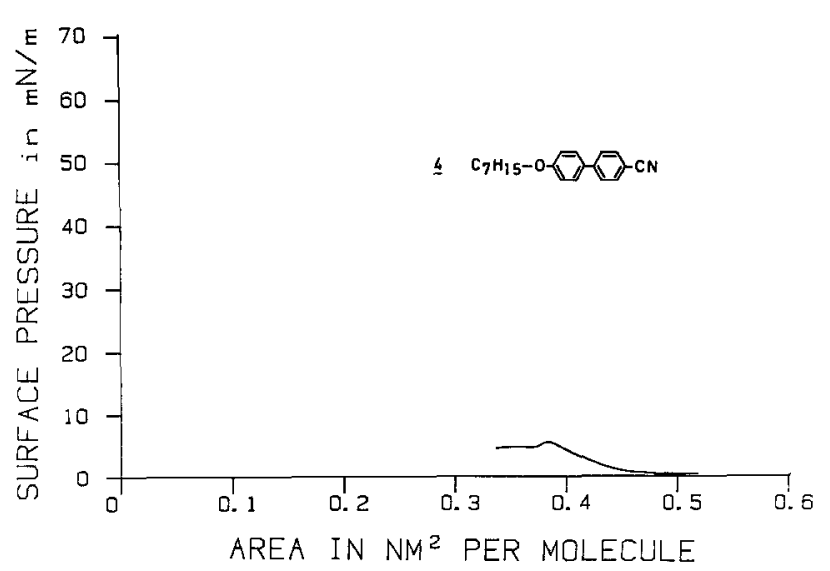

Fig. 4. Surface pressure-area diagrams of 4 at $20^{\circ} \mathrm{C}$

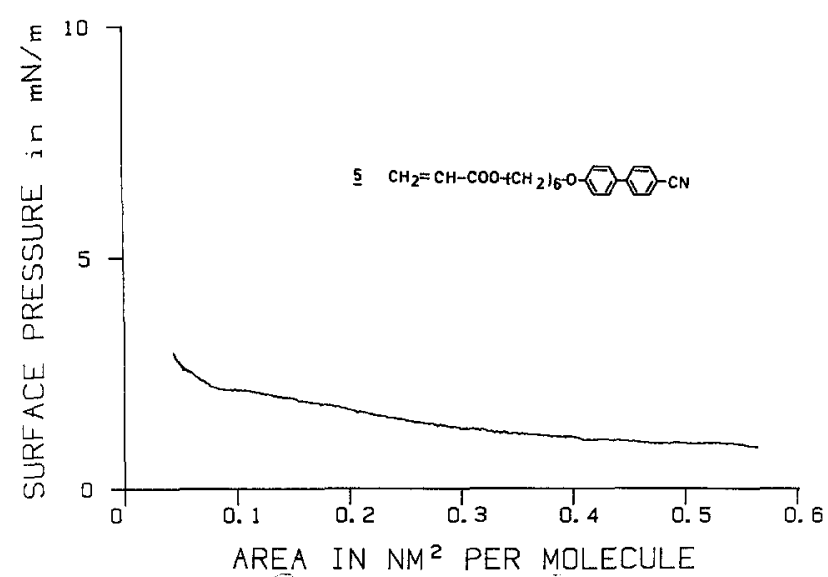

Fig. 5. Surface pressure-area diagram of 5 at $20^{\circ} \mathrm{C}$

trast to this interpretation of the arrangement, recent UV/Vis spectroscopic studies $[31,35]$ on monolayers of 3 point to a horizontal arrangement of the chromophores at the water surface. This discrepancy cannot be explained yet.

The $\pi$-A diagrams of the two-headed amphiphilic mesogens 5 and 6 are shown in Figures 5 and 6 . The diagrams indicate that no defined monolayer is formed. There is a slight increase of the surface pressure with increasing surface concentration of 5 and 6 , but no collapse point could be observed.

\section{Spreading behaviour of the discotic liquid crystals $7-11$}

So far there have only been a few reports about the spreading behaviour of discotic LCs [5, 7], but much

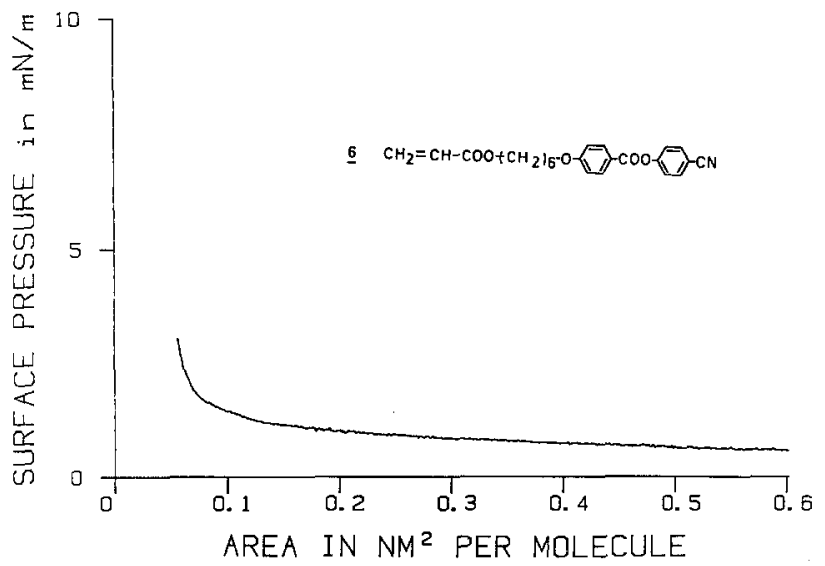

Fig. 6. Surface pressure-area diagram of 6 at $20^{\circ} \mathrm{C}$ 


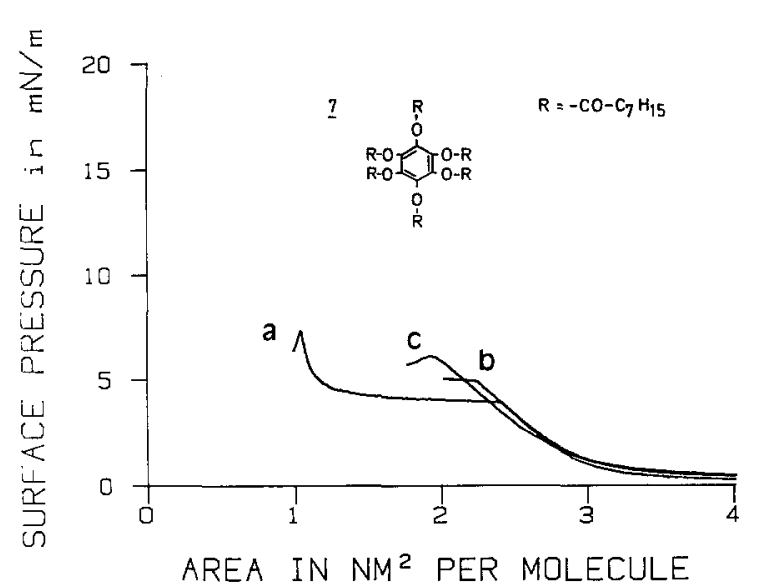

Fig. 7. Surface pressure-area diagrams of $7: a=a t 4^{\circ} \mathrm{C} ; b=$ at $20^{\circ} \mathrm{C}$; $\mathrm{c}=$ at $39^{\circ} \mathrm{C}$

work has been done on disc-shaped molecules such as porphyrins or phthalocyanines [32-41] which do not form thermotropic mesophases. However, the formation of defined monomolecular films at the gas-water interface is uncertain in some cases, considering the published $\pi$-A diagrams. Defined collapse points are missing and the surface pressure rises at very small areas per molecule only. In case of the investigated discotic LCs 7-11, all five compounds form monolayers with defined collapse points. Typically, the collapse pressures of the benzenehexaylhexakis(alkanoate)s (BHA) are well below $10 \mathrm{mN} / \mathrm{m}$, and the ones of the triphenylene derivatives are well below $20 \mathrm{mN} / \mathrm{m}$. The spreading of the two types of discotic LCs will be discussed separately.

\section{Spreading behaviour of the benzene derivates 7 and 8}

Figure 7 shows the $\pi$-A diagrams of the $\mathrm{BHA} 7$ with octanoyl chains. At temperatures above $5^{\circ} \mathrm{C}$, the curves show the formation of a highly compressible film, which collapses at about $2.5 \mathrm{~nm}^{2} /$ molecule at 5 $\mathrm{mN} / \mathrm{m}$. This spreading behaviour agrees well with $\pi$ A diagrams reported previously [5]. As already discussed by Rondelez [5], the collapse area would fit well with a flat orientation of the benzene ring at the water interface. This arrangement of the discotic LC 7 would formally agree with the arrangement of a conventional amphiphile: The benzene ring with all the six hydrophilic ester groups seems to act as the polar head group and is placed on the water surface, analogously as shown for 10 in Figure 12.

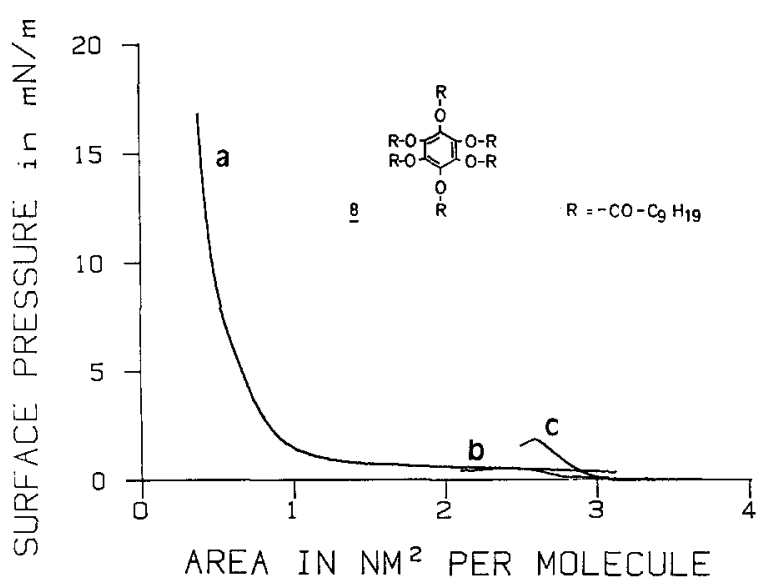

Fig. 8. Surface pressure-area diagrams of $8: a=a t 3^{\circ} \mathrm{C} ; b=$ at $20^{\circ} \mathrm{C}$; $\mathrm{c}=$ at $38^{\circ} \mathrm{C}$

At temperatures below $5^{\circ} \mathrm{C}$, a phase transition is observed at $4 \mathrm{mN} / \mathrm{m}$ for the monolayer of 7 . The monolayer collapses at $4^{\circ} \mathrm{C}$ at $1.1 \mathrm{~nm}^{2} /$ molecule and at $8 \mathrm{mN} / \mathrm{m}$ (Fig. 7). Analogous phase transitions were reported for BHAs with pentanoyl, hexanoyl and heptanoyl chains at higher temperatures [5]. Considering the collapse area, the minimal area necessary for the packing of the six hydrocarbon chains would be 1.1 $\mathrm{nm}^{2} /$ molecule. This is just the collapse area observed. It would be difficult to fit in the aromatic core with the ester bonds additionally. Thus, in addition to the flat arrangement of the benzene cores, an "edge on" arrangement (upright position [5]) can be considered, as suggested for triphenylenes 9-11 below.

The $\pi$-A diagrams of the BHA 8 with decanoyl chains are presented in Figure 8. At temperatures above $5^{\circ} \mathrm{C}$, a monolayer seems to be formed. Above $30^{\circ} \mathrm{C}$, the monolayer is highly compressible, showing a collapse area of $2.6 \mathrm{~nm}^{2} /$ molecule and a collapse pressure of $2 \mathrm{mN} / \mathrm{m}$. The compressibility and the area occupied per molecule are very similar to those of the highly compressible phase of 7 above $5^{\circ} \mathrm{C}$, but the collapse pressure of the monolayer of 8 is lower. Decreasing the temperature, no phase transition is found for 8 as was for 7. Instead, the collapse area of 8 decreases continuously to $2 \mathrm{~nm}^{2} /$ molecule with decreasing collapse pressures (approx. $1 \mathrm{mN} / \mathrm{m}$ ). Below $5^{\circ} \mathrm{C}$, no monolayer is formed. A defined collapse point is missing and the rise of the surface pressure occurs at areas per molecule well below any packing possibility of a monolayer.

Comparing the $\pi$-A diagrams of 7 and 8 (Figs. 7,8 ) and the published $\pi$-A diagrams of BHAs [5], an unu- 


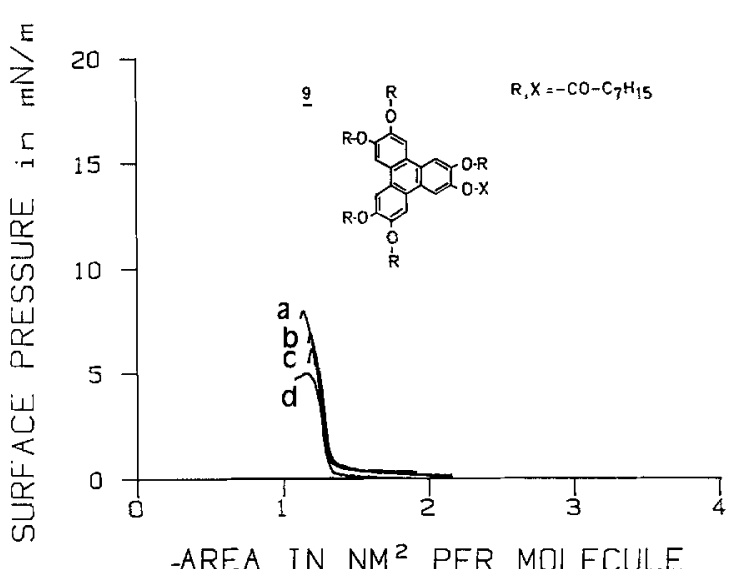

Fig. 9. Surface pressure-area diagrams of $9: a=a t ~^{\circ} \mathrm{C} ; \mathrm{b}=$ at $10^{\circ} \mathrm{C}$; $\mathrm{c}=$ at $20^{\circ} \mathrm{C} ; \mathrm{d}=40^{\circ} \mathrm{C}$

sual feature is obvious. There is a stability maximum of the monolayers, dependent on the hydrophobic chain length. The stability and the collapse pressures of the monolayers decrease with increasing chain length for the BHAs investigated. The BHA with six pentanoyl chains is the most stable [5]. Also, the monolayer phase transition temperatures decrease with increasing chain lengths. Both observations are in contrast to the usual behaviour of amphiphiles such as fatty acids or phospholipids [22]. As a flat arrangement of the aromatic cores on the water surface should favour increasing stability and transition temperatures with increasing chain length, the unusual spreading behaviour points to the "edge on" arrangement of the benzene cores in the tightly packed low compressible phase. A special interaction of the aromatic groups might overlay the hydrophobic effect.

\section{Spreading behaviour of the triphenylene deriva- tives 9-11}

The spreading behaviour of the triphenylenes 9 to 11 is shown in Figures 9-11. The $\pi-\mathrm{A}$ diagrams of all three discotic LCs show the formation of monolayers with a defined collapse point. Within the temperature ranges investigated $\left(1^{\circ} \mathrm{C}\right.$ to $40^{\circ} \mathrm{C}$ for 9 and $10^{\circ} \mathrm{C}$ to $40^{\circ} \mathrm{C}$ for 10 and 11 ), the collapse areas of the compounds do not change. The compressibility of the monolayers is low, thus pointing to a condensed phase. The collapse pressures decrease slightly with increasing temperature, a well known effect in condensed monolayers of conventional amphiphiles. The

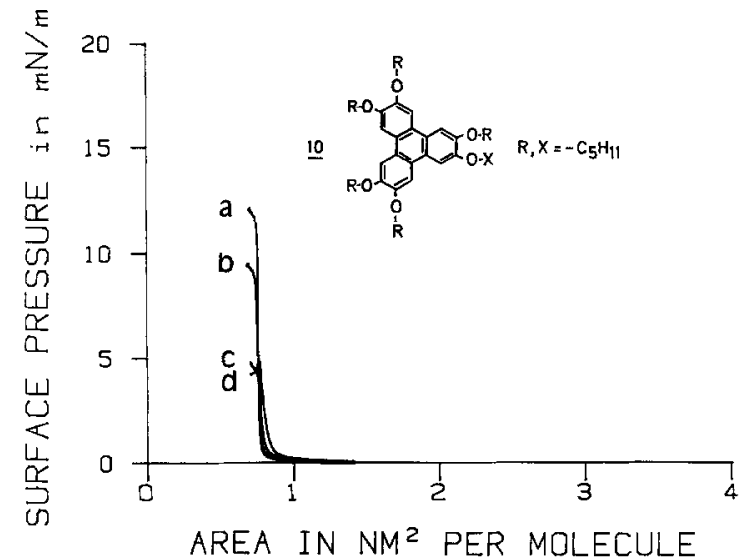

Fig. 10. Surface pressure-area diagrams of $10: a=a t 10^{\circ} \mathrm{C} ; b=a t$ $20^{\circ} \mathrm{C} ; \mathrm{c}=$ at $30^{\circ} \mathrm{C} ; \mathrm{d}=40^{\circ} \mathrm{C}$

collapse area of the hexaester 9 is $1.2 \mathrm{~nm}^{2} /$ molecule, the collapse pressure decreases from $8 \mathrm{mN} / \mathrm{m}$ to 5 $\mathrm{mN} / \mathrm{m}$ with increasing temperature (Fig. 9). The collapse area of the hexaether 10 is $0.73 \mathrm{~nm}^{2} /$ molecule, the collapse pressure decreases from $12 \mathrm{mN} / \mathrm{m}$ to $5 \mathrm{mN} / \mathrm{m}$ with increasing temperature (Fig. 10). Similarly, the collapse area of the pentaether-acetate 11 is $0.71 \mathrm{~nm}^{2} /$ molecule and the collapse pressure decreases from 13 $\mathrm{mN} / \mathrm{m}$ to $9 \mathrm{mN} / \mathrm{m}$ with increasing temperature (Fig. 11).

Considering the $\pi$-A diagrams, the collapse areas of all the triphenylenes are too small for a flat arrangement of the disc-shaped aromatic cores at the water surface. The low collapse areas cannot be understood assuming the conventional arrangement of amphi-

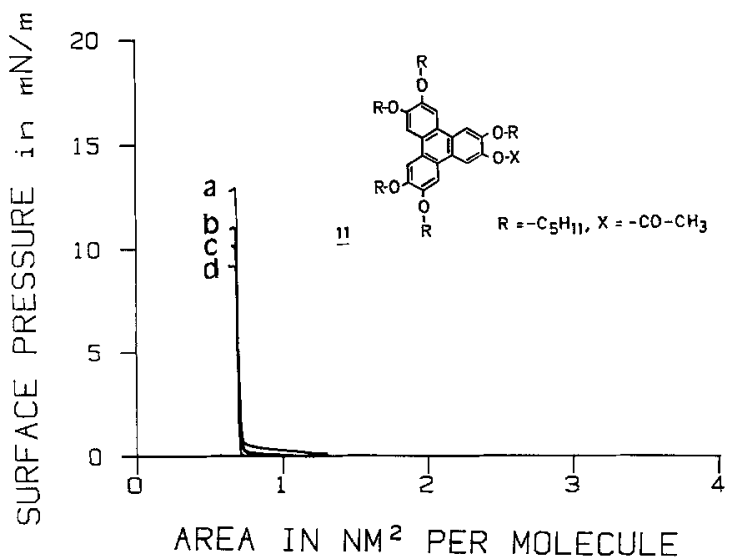

Fig. 11. Surface pressure-area diagrams of $11: a=$ at $10^{\circ} \mathrm{C} ; \mathrm{b}=$ at $20^{\circ} \mathrm{C} ; \mathrm{c}=$ at $30^{\circ} \mathrm{C} ; \mathrm{d}=40^{\circ} \mathrm{C}$ 


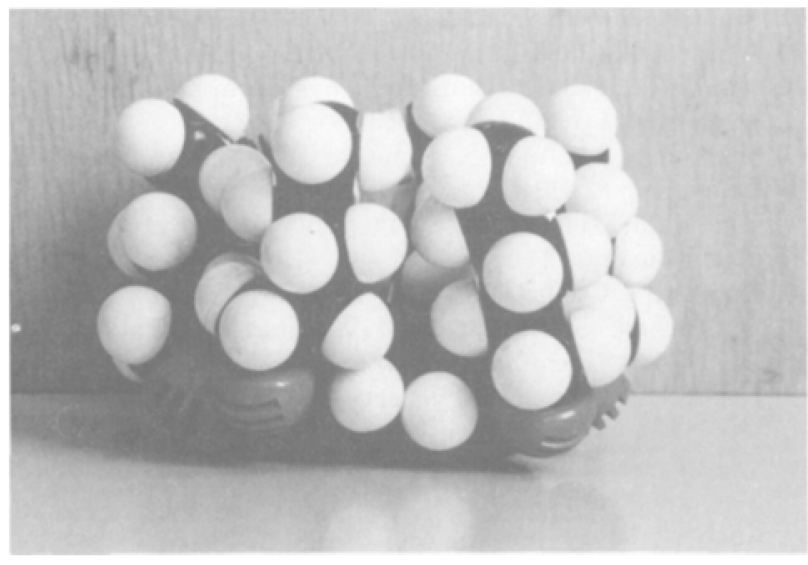

Fig. 12. Model of 10 at the air-water interface, assuming flat arrangement of the triphenylene core on the water surface

philes at the air-water interface, with all hydrophilic groups in contact with the water surface and the hydrophobic chains packed, as modelled for 10 in Figure 12. The six hydrocarbon chains alone require an area of approximately $1.1 \mathrm{~nm}^{2} /$ molecule, not taking into account any additional space for the triphenylene core. An unconventional model to explain the low collapse areas of 9-11 would be an "edge on" arrangement of the aromatic cores, with two hydrocarbon chains submerged in the water and two hydrophilic groups lifted off from the water surface (Fig. 13). The lift off of hydrophilic groups from the water surface is possible, as studies of the spreading behaviour of octadecanedioic acid monomethylester demonstrated [45]. An analogous model is discussed for the spreading behaviour of (tetra-t-butyl)copper-phthalocyanine [38]. Furthermore, the low compressibility of the monolayers of the triphenylenes 9-11 points to an interaction of the aromatic cores as well, best realizable by the "edge on" arrangement.

The "edge on" model is supported by the similarity of the $\pi$-A diagrams of the triphenylene ethers 10 and 11. The replacement of one hydrophobic pentyl group by one hydrophilic acetyl group does not change the spreading behaviour markedly. Strikingly, the reduced number of hydrophobic chains is not expressed in the $\pi$-A diagrams, since the collapse pressures and especially the collapse areas of 10 and 11 are comparable. Apparently, the spreading characteristics are mainly controlled by the triphenylene core. This result can be understood assuming "edge on" arrangement as shown in Figure 13, but not assuming flat arrangement of the aromatic cores as shown in

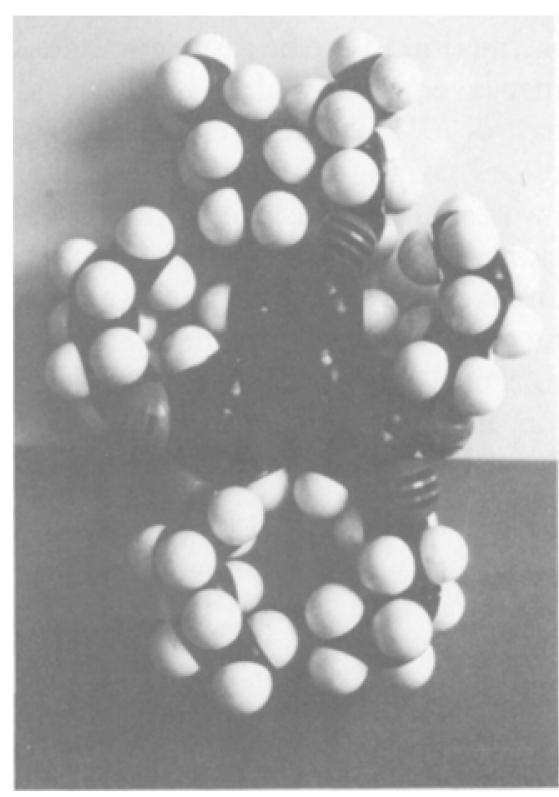

Fig. 13. Model of 10 at the air-water interface, assuming "edge on" arrangement of the triphenylene core on the water surface

Figure 12. The "edge on" model predicts that the pentaether 11 with less hydrophobic chains - and thus only one chain submerged in the water - forms more stable monolayers than the hexaether 10. Indeed, higher collapse pressures are experimentally found for the pentaether 11.

In analogy to the triphenylenes, the "edge on" arrangement of the benzene core with two hydrophobic chains submerged, would explain the observed abnormal phase transition behaviour of the BHAs. The densely packed "edge on" phase is favoured by relatively short chains. As with increasing chain length the hydrophobic effect becomes stronger, the submerging of two hydrophobic chains is prevented. Thus no densely packed phase can be formed for extended hydrophobic chains, as found.

It has to be emphasized, that by the $\pi$-A data only, no final statement concerning arrangement and packing of the discotic LCs can be made. Additional information about the orientation of the aromatic cores as provided by spectroscopic or X-ray scattering experiments is necessary.

In good agreement with the proposed "edge on" arrangement at the air-water interface are the results of preliminary Langmuir-Blodgett multilayer experiments. Multilayers can be built with 10 and 11 . Their layer spacings were determined by small angle X-ray 
scattering as $1.77 \mathrm{~nm}$ for 10 , and as $1.70 \mathrm{~nm}$ for 11 respectively. The spacings found can be easily correlated to the intercolumnar layer spacing of $1.64 \mathrm{~nm}$, found in the $D_{b o}$-mesophase of 10 [50]. These results strongly support the "edge on" arrangement of the original monolayers at the water surface, possibly implying lateral columnar packing [38] of the triphenylene cores. However, LB multilayers of the triphenylene ester 9 gave a layer spacing of $2.79 \mathrm{~nm}$, which differs substantially from the molecular spacings in its mesophase [43]. This deviation seems to be related to the differences in the spreading behaviour between triphenylene esters and ethers.

\section{Conclusions}

Calamitic and discotic liquid crystals were shown to form monolayers at the air-water interface. The use of polar calamitic mesogens as hydrophilic head groups results in classical monolayer properties. Tight packing of the hydrophobic chains can be achieved and the monolayer phase transition temperature is controlled by the length of the hydrophobic chains. The discotic LCs form monolayers as well. Whereas benzenehexayl hexakis(alkanoate)s behave at room temperature as would be expected from their amphiphilic structure, at low temperatures condensed-like phases with extremely small collapse areas are found. Triphenylenes show such tightly packed phases exclusively. The spreading data suggest an "edge on" arrangement of the aromatic cores at the water surface, allowing interactions of the cores, but forcing two hydrophobic chains into the subphase. This arrangement results in less stable monolayers with increasing chain length.

\section{References}

1. Fendler JH (1982) Membrane Mimetic Chemistry, J Wiley, New York

2. Kelker H, Hatz R (1980) Handbook of Liquid Crystals, Verlag Chemie, Weinheim

3. Dörfler HD, Kerscher W, Sackmann H (1972) Z Phys Chem 251:314

4. Diep-Quang H, Überreiter K (1980) Coll \& Polym Sci 258:1055

5. Rondelez F, Koppel D (1982) J Physique 43:1371

6. Daniel MF, Lettington OC, Small SM (1983) Mol Cryst Liq Cryst $96: 373$

7. Suresh KA, Blumstein A, Rondelez F (1985) J Physique 46:453

8. Okahata Y, Kunitake T (1980) Ber Bunsenges Phys Chem $84: 550$

9. Steven JH, Hann RA, Barlow WA, Laird T (1983) Thin Solid Films 99:71
10. Mooney III WF, Brown PE, Russel JC, Costa SB, Pedersen LG, Whitten DG (1984) J Am Chem Soc 106:5659

11. Möbius D (1978) Ber Bunsenges Phys Chem 82:848

12. Heesemann J (1980) J Am Chem Soc 102:2167

13. Shimomura M, Ando R, Kunitake T (1983) Ber Bunsenges Phys Chem 87:1134

14. Blinov LM, Davydova NN, Lazarev VV, Yudin SG (1982) Sov Phys Solid State 24:1523

15. Kunitake T, Okahata Y (1980) J Am Chem Soc 102:549

16. Sprintschnik G, Sprintschnik HW, Kirsch PP, Whitten DG (1977) J Am Chem Soc 99:4947

17. Gaines GL, Behnken PE, Valenty SJ (1978) J Am Chem Soc 100:6549

18. Tieke B, Enkelmann V, Kapp H, Lieser G, Wegner G (1981) J Macromol Sci A15:1045

19. Koch H, Laschewsky A, Ringsdorf H, Teng K, Makromol Chem, in press

20. Laschewsky A, Ringsdorf H, Schmidt G, Thin Solid Films, in press

21. Nakanishi T (1984) J Chem Soc Chem Commun 1543

22. Gaines GL (1966) Insoluble Monolayers at the Liquid-Gas Interface, Interscience, New York

23. Pindak R, Moncton D (1982) Physics Today 35(5):57

24. Chandrasekhar S, Sadashiva BK, Suresh KA, Madhusudana NV, Kumar S, Shashidar R, Venkatesh G (1979) J Physique Coll C3,40:120

Chandrasekhar S (1983) Phil Trans R Sóc Lond A 309:93

25. Billard J, Dubois JC, Nguyen Huu Tinh, Zann A (1978) Nouv J Chim 2:535

26. Claisen L (1919) Liebigs Ann Chem 418:97

27. Shibaev VP, Kostromin SG, Platé NA (1982) Eur Polymer J 18:651

Ringsdorf H, Schmidt HW, Baur G, Kiefer R (1985) (ed) Chapoy LL, in Recent Advances in Liquid Crystalline Polymers, Elsevier, London

28. Portugall M, Ringsdorf H, Zentel R (1982) Makromol Chem 183:2311

29. Kreuder W, Ringsdorf H(1983) Makromol Chem Rapid Commun 4:807

Kreuder W, Ringsdorf H, Tschirner P (1985) Makromol Chem Rapid Commun 6:367

30. Albrecht $O$ (1983) Thin Solid Films 99:227

31. Möbius D, Orrit M, Grüniger H, Meyer H, Thin Solid Films, in press

32. Ruaudel-Teixier A, Barraud A, Belbeoch B, Rouillay M (1983) Thin Solid Films 99:33

33. Jones R, Tredgold RH, Hodge P (1983) Thin Solid Films 99:25

34. Baker S, Petty MC, Roberts GG, Twigg MV (1983) Thin Solid Films 99:53

35. Grüniger H, Möbius D, Meyer H (1983) J Chem Phys 79:3701

36. Snow AW, Jarvis NL (1984) J Am Chem Soc 106:4706

37. Whitten DG, Eaker DW, Horsey BE, Schmehl RH, Worsham PR (1978) Ber Bunsenges Phys Chem 82:858

38. Fryer JR, Hann RA, Eyres BL (1985) Nature 313:382

39. Möhwald H, Miller A, Stich W, Knoll W, Ruaudel-Teixier A, Lehmann T, Fuhrhop JH, Thin Solid Films, in press

40. Alexander AE, J Chem Soc 1937:1813

41. Tweet AG, Gaines jr GL, Bellamy WD (1964) J Chem Phys 41:1008

42. Demus D, Zaschke $H$ (1984) Flüssige Kristalle in Tabellen II, VEB Grundstoffindustrie, Leipzig 
43. Destrade C, Nguyen Huu Tinh, Gasparoux H, Malthete J, Levelut AM (1981) Mol Cryst Liq Cryst 71:111

44. Attaching strongly hydrophilic groups to discs leads to lyotropic discotic mesophases:

Gaspard S, Hochapfel A, Viovy R (1979) C R Hebd Séances Acad Sci C289:387

Boden N, Bushby RJ, Hardy C (1985) J Physique Lett 46:L325

Keller-Griffith R, Ringsdorf H, Vierengel A, J Am Chem Soc, in press

45. Vogel V, Möbius D, Thin Solid Films, in press

46. Musgrave OC, Webster CJ, J Chem Soc (C) 1971:1397

47. Neifert IE, Bartow E (1943) J Am Chem Soc 65:1770

48. Fatiadi AJ, Sager WF, Organic Synthesis Collective Vol V, 595

49. Hatada M, Nishii M, Hirota K (1972) J Coll \& Interf Sci 454:502
50. Levelut AM (1979) J Physique Lett 40:L81

Authors' address:

H. Ringsdorf

Universität Mainz

Institut für Organische Chemie

Postfach 3980

J.-J.-Becher-Weg 18-20

D-6500 Mainz, F.R.G. 